\title{
RECONHECIMENTO DE SOLOS POR MEIO DE RESISTIVIDADE ELÉTRICA E RADIAÇÃO GAMA
}

\author{
CARLOS TADEU CARVALHO DO NASCIMENTO, AUGUSTO CESAR BITTENCOURT PIRES \\ \& ROBERTO ALEXANDRE VITÓRIA DE MORAES
}

\begin{abstract}
SOIL SURVEY BY DC ELECTRICAL RESISTIVITY AND GAMMA-RAY SPECTROMETRY The purpose of this work is to present procedures for reconnaissance of soils, based on DC electrical resistivity measurements and gamma-ray spectrometry. The study area has $5 \mathrm{~km}^{2}$ and is located in the Jardim Botânico de Brasília (Brazil), an environmental conservation area. In this area, resistivity measurements were obtained at 190 different points, and radiometric measurements (uranium, thorium, potassium, and total count) at 9 different points. Apparent resistivity values below 15000 Ohm.m were observed in clay soils and between 15000 and $30000 \mathrm{Ohm} . \mathrm{m}$ in sandy soils. It was also observed that radioactivity from clay soils is between 8000 and $14000 \mathrm{cps}$ at total count, while in sandy soils, this value is below $8000 \mathrm{cps}$. For the study area, although the clay soils are more radioactive, the K/U and K/Th ratios are higher in sandy soils. This fact can be related with differences in mineralogical composition of these materials. The processing of data produced an apparent resistivity map for the study area and its integration with radiometric data using a statistical procedure, the cluster analysis. The products of processing were compared with the soil map for to correlate the geophysical units with different kinds of soils.
\end{abstract}

Keywords: geophysics, resistivity, gamma-ray spectrometry, cluster analysis, tropical soils.

Resumo O objetivo deste trabalho é apresentar procedimentos para reconhecimento de solos, baseados em medições de sua resistividade elétrica e de sua radioatividade natural. A área de estudo possui $5 \mathrm{~km}^{2}$ e faz parte do Jardim Botânico de Brasília, uma unidade de conservação ambiental. Neste local obtiveram-se medidas de resistividade em 190 pontos distintos e ainda medidas radiométricas (urânio, tório, potássio e contagem total) em 9 pontos distintos. Observaram-se valores de resistividade aparente inferiores a 15000 Ohm.m para solos argilosos e entre 15000 e 30000 Ohm.m para solos arenosos. Observou-se também que a radioatividade dos solos argilosos é mais elevada, entre 8000 e $14000 \mathrm{cps}$ na contagem total, ao passo que nos arenosos, este valor situa-se abaixo de $8000 \mathrm{cps}$. Na área de estudo, embora os solos argilosos sejam os mais radioativos, verificou-se que as razões K/U e K/Th são mais elevadas nos solos arenosos, fato este que pode estar relacionado com diferenças na composição mineralógica destes materiais. O processamento dos dados incluiu a confecção de um mapa de resistividade aparente para a área de estudo e sua integração com os dados radiométricos por meio de um procedimento estatístico, a análise de grupos. Os produtos obtidos foram comparados com o mapa de solos disponível, de modo a estabelecer correlações entre os diferentes solos e os padrões observados nos mapas geofísicos.

Palavras-chave: geofísica, resistividade, gamaespectrometria, análise de agrupamentos, solos tropicais.

INTRODUÇÃO Métodos geofísicos são largamente utilizados em trabalhos relacionados com mapeamento geológico e prospecção mineral. Desde a década de 1970 eles também vêm sendo utilizados em estudos voltados para prevenção e monitoramento de aspectos relativos à poluição ambiental. No campo da pedologia, têm sido utilizados para medir parâmetros dos solos, como a umidade e a salinidade. No entanto, existem poucos trabalhos relatando a utilização de geofísica no estudo e manejo de solos brasileiros, em particular dos latossolos.

No Distrito Federal, latossolos cobrem aproximadamente a metade do território. Em locais como a bacia do rio Jardim, estes solos são utilizados para agricultura. Eles cobrem também expressivas áreas dentro de unidades de conservação como o Parque Nacional de Brasília e a Reserva Ecológica do IBGE (Instituto Brasileiro de Geografia e Estatística).

A determinação das características destes solos, por meio de análises físicas, químicas e morfológicas em amostras pontuais, tem sido rotineiramente executada. Entretanto, eles mostram grandes variações estruturais, texturais e composicionais o que dificulta a generalização dos resultados destas análises.

Neste contexto, a geofísica se insere como meio de obter estimativas sobre as propriedades físicas do solo, de maneira rápida, não invasiva e possibilitando a cobertura de extensões relativamente grandes. Não se pretende com isto substituir os métodos convencionais de estudo, mesmo porque não há substituto para alguns tipos de análise, mas sim demonstrar as vantagens deste tipo de investigação indireta.

Dentre todos os métodos geofísicos optou-se por trabalhar principalmente com o elétrico de corrente contínua e com a gamaespectrometria. Esta escolha deveu-se a uma série de fatores relacionados com existência de literatura adequada, disponibilidade de equipamentos, procedimentos envolvidos nas etapas de aquisição e processamento dos dados, e finalmente, potencial e limitações dos produtos finais gerados. 
A área de estudo foi o Jardim Botânico de Brasília devido, principalmente, à existência de um mapa detalhado dos solos daquele local, bem como a disponibilidade de dados de análises físicas e químicas dos solos cartografados. Outro fator que determinou a escolha deste local foi o fato de tratar-se de uma unidade de conservação ambiental, portanto com um mínimo de interferência humana.

Os procedimentos empregados neste estudo consistiram da aquisição dos dados geofísicos, resistividade elétrica aparente e radiação gama natural, seguida do processamento destes dados, gerando gráficos e mapas ilustrativos da variação dos parâmetros medidos, conforme o tipo de solo. Finalmente efetuou-se uma integração destes dados por meio de análise de agrupamentos e comparação do produto gerado com o mapa de solos disponível.

ÁREA DE ESTUDO O Jardim Botânico de Brasília (JBB) é um órgão vinculado à Secretaria do Meio Ambiente e Recursos Hídricos do Distrito Federal. Ele localiza-se na porção central do DF, ocupando cerca de $45 \mathrm{~km}^{2}$ (Fig. 1). Até 1985 todo a área do JBB era uma única unidade de conservação ambiental, denominada Estação Florestal Cabeça de Veado, criada em 1960, simultaneamente à inauguração de Brasília. Em 1985, uma nova legislação redefiniu o uso daquela região, criando of icialmente o JBB e abrindo uma área de $5 \mathrm{~km}^{2}$ aos visitantes (SEMATEC 1994).

A porção sul do JBB, com $40 \mathrm{~km}^{2}$, denominada Estação Ecológica, foi definida como área de pesquisa básica e aplicada em ecologia, cujo acesso só é permitido mediante autorização da administração. As linhas prioritárias de pesquisa na estação são sociologia vegetal, florística, taxonomia, e aquelas relacionadas à conservação de espécies da fauna e da flora do cerrado brasileiro.

$\mathrm{O}$ mapa ilustrado na figura 2 corresponde à área de visitação do JBB, na qual se insere a área de trabalho. A área de visitação é limitada ao norte por uma área residencial de Brasília e a leste pela Estrada Parque Contorno. Os limites oeste e sul são fronteiros com a Estação Ecológica. A altitude varia de $1160 \mathrm{~m}$ próximo à EPCT até 1050 m no vale do Córrego Cabeça de Veado.

A porção norte do JBB, atualmente aberta à visitação, foi alvo de um levantamento pedológico com o intuito de melhor planejar as atividades a serem ali desenvolvidas (Cavedon \& Sommer 1990). Este trabalho incluiu a descrição de 19 perfis de solo, 7 dos quais na área de estudo, com amostragem de cada horizonte identificado para fins de análise. O principal resultado deste trabalho foi a elaboração de um mapa de solos em escala 1:10.000, no qual é possível visualizar diversas unidades de mapeamento, entre latossolos, cambissolos e outros grupos de menor expressão em área. Este mapa está parcialmente reproduzido na figura 2.

Algumas análises granulométricas feitas em latossolos do Distrito Federal têm sido questionadas no que diz respeito a quantidades relativamente grandes de silte e areia. Argumenta-se que estas partículas mais grossas possam ser estruturas de agregação de argila, que não foram completamente dispersadas durante as análises (Santos, 1996). Outro problema diz respeito à ocorrência de descontinuidade na curva granulométrica ao se passar do peneiramento fino (frações maiores que $(0,075 \mathrm{~mm}$ ) para o ensaio de sedimentação (fração menor que $0,075 \mathrm{~mm}$ ) (Palocci et al. 1998). Por este motivo optou-se por trabalhar com o parâmetro argila+silte ao invés de considerar estas duas frações separadamente.

No mapa de solos do JBB destacam-se as unidades C, RL, LV e LVA. C corresponde a cambissolo, com teor de argila+silte de $36 \%$, localmente cascalhento (C2). RL corresponde a solo litólico, assentado diretamente sobre quartzito, com teor de argila+silte de

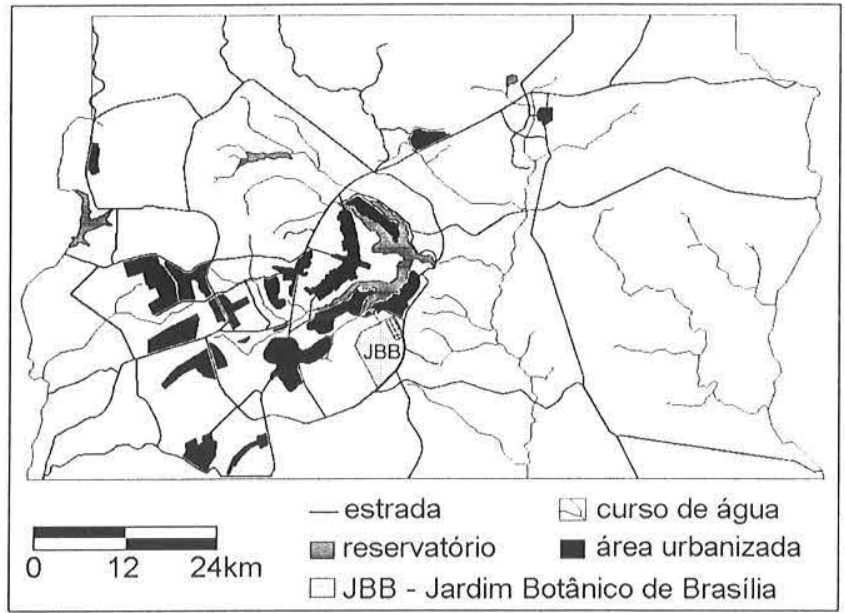

Figura l-Mapa do Distrito Federal, mostrando a localização da área de estudo (JBB). Modificado de CODEPLAN (1984).

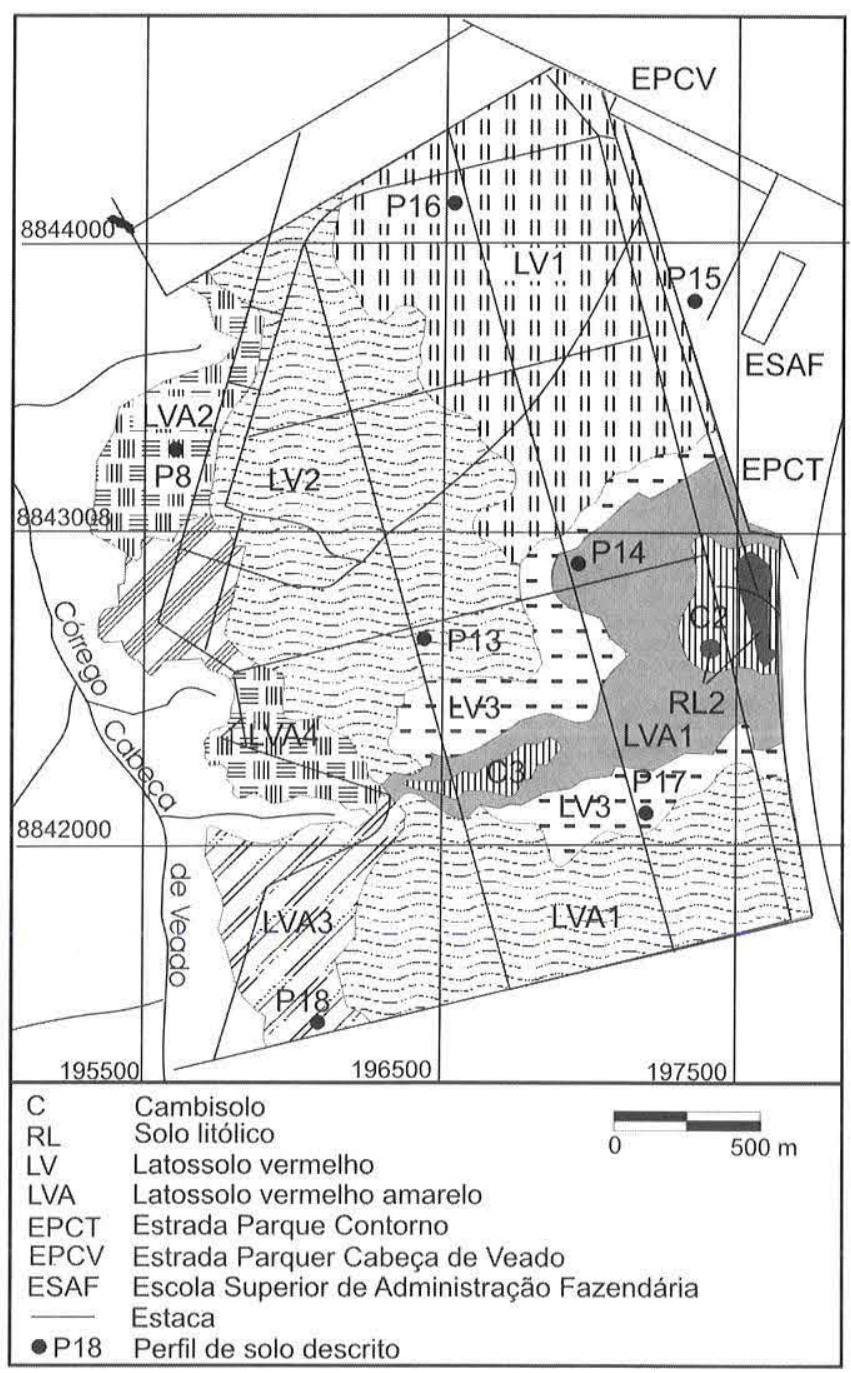

Figura 2 - Mapa de solos do Jardim Botânico de Brasília. Modificado de Cavedon \& Sommer (1990). 
$40 \%$, com cascalho e afloramentos de rocha. LV corresponde a latossolo vermelho, com teor de argila+silte variando entre $91 \%$ (LVI) até 19\% (LV3). LVA corresponde a latossolo vermelho amarelo, com teor de argila+silte variando entre $21 \%$ (LVA1) até $74 \%$ (LVA3).

Verifica-se, por meio dos dados disponíveis, que existe uma correlação negativa entre o teor de argila+silte e a condutividade hidráulica. O LVI tem $91 \%$ de argila+silte e condutividade hidráulica de $20,85 \mathrm{~cm} / \mathrm{h}$. O LV 3 tem $19 \%$ de argila+silte e condutividade hidráulica de $41,18 \mathrm{~cm} / \mathrm{h}$. O LVAI tem $21 \%$ de argila+silte e condutividade de $32,87 \mathrm{~cm} / \mathrm{h}$. O LVA 3 tem $74 \%$ de argila+silte e condutividade de $19,26 \mathrm{~cm} / \mathrm{h}$.

Considerando apenas o horizonte mais superficial dos perfis descritos na área de estudo (Fig. 2), observa-se que os LV são os que, em média, têm maior capacidade de troca catiônica (12,96 meq/lo0g) e maior teor de matéria orgânica $(3,75 \%)$. Os LVA têm capacidade de troca catiônica de $10,12 \mathrm{meq} / 100 \mathrm{~g}$ e teor de matéria orgânica de 2,69\%. O cambissolo é o que tem menor capacidade de troca $(6,63 \mathrm{meq} / 100 \mathrm{~g})$ e menor teor de matéria orgânica $(1,78 \%)$.

MÉTODOS UTILIZADOS A resistividade elétrica de uma substância é definida como a resistência à passagem de corrente e é expressa em unidade de resistência multiplicada por unidade de comprimento (Ohm.m) (Koefoed 1979).

As rochas e os solos, em geral, são bastante resistivos, mas a presença de substâncias metálicas, e principalmente a presença de líquidos em poros e fraturas, normalmente determinam uma redução da resistividade (Orellana 1972, Telford et al. 1985).

Conforme Fukue et al. (1999), a resistividade do solo depende, no mínimo, dos seguintes fatores: permeabilidade; grau de saturação: resistividade do líquido nos poros; porosidade; tamanho, forma e distribuição das partículas sólidas; espessura e composição da camada catiônica dos argilominerais.

No método elétrico de corrente contínua, trabalha-se com dois eletrodos de corrente ou de energização (A e B) e dois eletrodos de potencial ou de medição ( $\mathrm{Me} \mathrm{N}$ ), os quatro fixados na superfície do terreno segundo diversos arranjos, colineares ou não (Fig. 3). Através dos eletrodos A e B aplica-se uma diferença de potencial, criando-se um campo elétrico, de modo que uma corrente elétrica contínua começa a percorrer o terreno. $\mathrm{O}$ valor da corrente é medido e registrado. Utilizando os eletrodos $\mathrm{M}$ e $\mathrm{N}$, mede-se uma diferença de potencial que se estabelece no terreno e que está associada à passagem da corrente. Deve-se notar que o solo já possui um potencial elétrico natural, potencial espontâneo, o qual deve ser descontado da medição feita com os eletrodos $\mathrm{M}$ e $\mathrm{N}$. Conhecendo-se a corrente estabelecida, a geometria da disposição dos eletrodos e o potencial medido entre os eletrodos $\mathrm{M}$ e N, pode-se calcular um valor de resistividade elétrica, que, por estar sendo medido em um meio heterogêneo e anisotrópico, e por ser função do arranjo de eletrodos, é dita aparente (Orellana 1972, Telford et al. 1985).

Existem diferentes maneiras de dispor os eletrodos uns em relação aos outros, bem como de transportá-los sobre o terreno a ser estudado. Um dos arranjos mais comuns em trabalhos de geofísica rasa é aquele idealizado pelo norte-americano Frank Wenner, em 1915, e que leva o seu nome. Este arranjo caracterizase pela disposição equiidistante dos eletrodos de potencial e de corrente, segundo uma linha reta. Habitualmente, os eletrodos A e B situam-se nos extremos do arranjo, enquanto $\mathrm{M}$ e $\mathrm{N}$ situam-se próximo ao centro (Fetter 1994, Koefoed 1979, Orellana 1972, Van Nostrand \& Cook 1966).

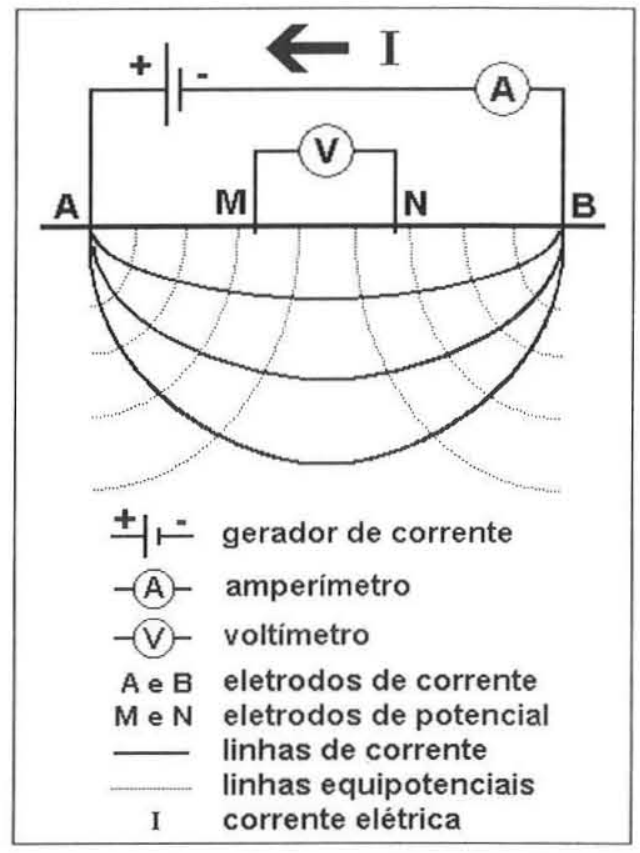

Figura 3 - Distribuição habitual dos eletrodos no método elétrico de corrente contínua.

O arranjo de Wenner é normalmente utilizado para a perfilagem elétrica horizontal, que é a determinação da variação lateral da resistividade, a uma profundidade constante. Na perfilagem, também conhecida como caminhamento elétrico, os quatro eletrodos são deslocados em grupo sobre o terreno, de forma a obter um conjunto de medidas regularmente distribuídas ao longo de uma dada direção. Quando a densidade de medições numa área permite, os resultados podem ser apresentados na forma de mapas. A profundidade de investigaçãoé proporcional ao espaçamento entre eletrodos. Quando são utilizados dois ou mais espaçamentos no local de cada medida, então ao final do trabalho podem ser apresentados perfis e/ou mapas correspondentes a duas ou mais profundidades. A perfilagem elétrica horizontal não deve ser confundida com a perfilagem elétrica de poço, na qual as medições de resistividade são executadas no interior de um furo de sonda.

Admite-se que quanto maior o espaçamento entre os eletrodos, maior a profundidade alcançada. Em pesquisas geológicas ou hidrogeológicas, este espaçamento pode variar desde alguns metros até vários quilômetros (Telford et al. 1985). Em pesquisas relacionadas com caracterização de solos, o espaçamento entre os eletrodos pode ser de poucos centímetros. Rhoades \& Ingvalson (1971) relatam a execução de perfilagens elétricas horizontais, nas quais o espaçamento entre os eletrodos foi de $0,3 \mathrm{~m}$. Robain et al. (1996), trabalhando em solos lateríticos, na República de Camarões, África Central, utilizaram arranjo de eletrodos com espaçamento de $0,1 \mathrm{~m}$ para obter medidas de resistividade ao longo das paredes de poços abertos para descrição de perfis de solo.

No caso do arranjo de Wenner, as estimativas da profundidade relacionadas com uma dada distância "a" entre dois eletrodos quaisquer variam entre $a, a / 2$ e $a / 3$, sendo que o valor $a / 2$ parece ser a estimativa mais comum (Apparao 1991, Barker 1989, Roy \& Apparao 1971, Roy \& Elliot 1981). Cabe lembrar que este trabalho está sendo executado com corrente contínua, portanto com freqüência igual a zero. Deste modo, estimativas da profundidade de 
atenuação do sinal eletromagnético que consideram o valor da frequiência não são aplicáveis. A determinação mais correta das profundidades investigadas é obtida por meio da comparação dos dados de campo com modelos teóricos da estratificação na subsuperfície, no processo conhecido como inversão.

Medidas radiométricas são utilizadas no Brasil desde 1950 como instrumento de prospeç̧ão mineral. Em meados da década de 1970, este tipo de informação começou a ser utilizado como auxílio ao mapeamento geológico. Isto é possível porque os níveis radioativos das rochas podem ser correlacionados com sua idade e forma de ocorrência (Vasconcellos et al. 1994).

Raios gama são uma forma de radiação eletromagnética com comprimento de onda entre $10^{-14} \mathrm{e} 10^{-8} \mathrm{~m}$. Estes raios são emitidos durante o decaimento radioativo de elementos usualmente presentes em todos os solos e rochas, ainda que em quantidades reduzidas. As principais fontes de radiação são o ${ }^{40} \mathrm{~K}$ e as séries do ${ }^{238} \mathrm{U}$ e do ${ }^{232} \mathrm{Th}$. Na crosta terrestre $\mathrm{K}$, U e Th têm abundâncias respectivas de $3 \%, 3$ ppm e 12 ppm. $\mathrm{O}^{40} \mathrm{~K}$ corresponde a $0,012 \%$ do potássio total, o ${ }^{238} \mathrm{U}$ corresponde a 99,3\% do urânio total e o ${ }^{232}$ Th a $100 \%$ do tório total (Wilford et al. 1997).

Noventa porcento dos raios gama são emanados pela camada superficial de solo ou rocha, compreendida entre 30 e $45 \mathrm{~cm}$ de profundidade. A intensidade desta radiação se relaciona com a mineralogia e a química das rochas ou materiais originais e com o tipo de intemperismo atuante sobre estes. K é um constituinte comum de argilominerais ao passo que $\mathrm{U}$ e $\mathrm{Th}$ podem ser retidos por óxidos de ferro e também por argilominerais (Wilford et al. 1997).

A gamaespectrometria mede a concentração de $\mathrm{K}$, U e Th em rochas e solos por meio da detecção e quantificação da radiação gama natural. $\mathrm{O}^{40} \mathrm{~K}$ emite raios gama quando decai para ${ }^{40} \mathrm{Ar}$. A energia da radiação emitida é de $1,46 \mathrm{MeV}$. As concentrações de U e Th são medidas mais complexas, por que $\mathrm{O}^{238} \mathrm{Ue} \mathrm{o}{ }^{232} \mathrm{Th}$ decaem por meio de uma série de nuclídeos filhos até alcançarem isótopos de $\mathrm{Pb}$ estáveis. A energia da radiação diagnóstica do ${ }^{238} \mathrm{U}$ é 1,76 $\mathrm{MeV}$ e associa-se ao nuclídeo ${ }^{214} \mathrm{Bi}$. A energia da radiação diagnóstica do ${ }^{232} \mathrm{Th}$ é de $2,62 \mathrm{MeV}$ e associa-se ao nuclídeo ${ }^{208} \mathrm{Tl}$ (Wilford et al. 1997).

As intensidades de emissão fornecem informações sobre a distribuição dos três elementos radioativos mais comuns. As finalidades de se realizarem medidas gamaespectrométricas relacionam-se com a caracterização de litologias, e com a identificação de processos supérgenos que possam causar a remoção e/ou concentração destes elementos. No entanto, existem imprecisões associadas à mobilidade dos elementos formados durante $o$ decaimento, à radiação de fundo (background), ao tamanho e a geometria do alvo, à qualidade do detector e finalmente em relação à interferência de produtos da série do ${ }^{232} \mathrm{Th}$ na série do ${ }^{238} \mathrm{U}$ e de produtos das séries do ${ }^{232} \mathrm{Th}$ e do ${ }^{238} \mathrm{U}$ no ${ }^{40} \mathrm{~K}$ (Hansen 1975, Minty 1997).

Gamaespectrômetros são equipamentos que separam a energia da radiação gama em janelas ou faixas. O detetor, normalmente um cristal de iodeto de sódio ativado por tálio ( $\mathrm{NaI}(\mathrm{Tl})$ ), absorve a radiação gama e a transforma em pulsos luminosos ou cintilações. Estas cintilações são convertidas em sinais elétricos proporcionais à intensidade da luz. Em seguida, os sinais são separados em classes, dependendo da magnitude, de modo a se obter um espectro de energia dos raios gama incidentes. Um processo de calibração permite que a quantidade da radiação com energias de 1,46 MeV, I,76 MeV e 2,62 MeV, medida em cintilações por segundo (cps), seja expressa em percentagem (caso do K), ou ppm (caso

\section{do Ue Th) (Hansen 1975).}

PROCEDIMENTOS Durante os trabalhos no JBB, utilizou-se um resistivímetro modelo Geopulse, fabricado por Campus Geophysical Instruments, Inglaterra. Trata-se de um equipamento projetado para trabalhar como um sistema do tipo multieletrodo no qual, 25 eletrodos, com separação de 1 metro, são conectados de forma simultânea e independente ao resistivímetro por meio de um cabo especial. Um microcomputador é conectado ao Geopulse, controlando seu funcionamento mediante programa específico e, principalmente ativando e desativando conjuntos de eletrodos, de forma a simular o deslocamento de apenas quatro eletrodos no terreno. Este tipo de equipamento possibilita a obtenção de seções elétricas, representações gráficas da variação da resistividade na subsuperfície em duas dimensões, comprimento e profundidade.

O Geopulse é alimentado por bateria automotiva de $12 \mathrm{~V}$, tem potência de $18 \mathrm{~W}$ e um sistema automático de regulagem da tensão de saída, cujo valor é ajustado de modo a se obter um valor de corrente entre os eletrodos A e B previamente estabelecido e que pode ser de 1,2, 5, 10,20, 50 ou $100 \mathrm{~mA}$.

A compensação do potencial elétrico natural é feita de modo automático durante a execução de cada leitura. O valor fornecido corresponde à resistência elétrica $(\mathrm{Ohm})$, que expressa o quociente entre o potencial estabelecido entre os eletrodos $\mathrm{M}$ e $\mathrm{N}$ e a corrente que circula através dos eletrodos A e B. Este valor é multiplicado pelo fator de geometria do arranjo empregado e com isto obtém-se o valor da resistividade do meio.

No início dos trabalhos, considerou-se a hipótese de que seções elétricas permitissem a visualização dos horizontes de solo. Contudo, os modelos gerados em diversos testes mostraram que, para tornar esta visualização possível, seria necessário utilizar eletrodos com espaçamento inferior a 1 metro. Isto ocorre porque os horizontes superficiais do solo costumam ter poucos centímetros de espessura. No JBB, é comum que nos primeiros 50 centímetros do perfil de solo estejam presentes até três horizontes, e justamente esta porção do perfil não foi visualizada nos modelos obtidos.

A falta de correspondência entre os modelos geoelétricos e os perfis de solo descritos, associada à dificuldades técnicas para instalar e transportar o sistema multieletrodo na área de estudo, bem como para trabalhar com espaçamentos inferiores a 1 metro, levou à opção por um sistema mais prático e ágil. A solução encontrada foi empregar apenas quatro eletrodos conectados diretamente ao resistivímetro e dispostos segundo o arranjo de Wenner. Julgou-se que um espaçamento de 2 metros fosse adequado ao objetivo de construir um mapa de resistividade aparente do JBB para comparação com o mapa de solos disponível. O valor da corrente elétrica durante a maior parte do trabalho foi de $1 \mathrm{~mA}$. Eventualmente empregaram-se valores mais elevados, de até $5 \mathrm{~mA}$. Este arranjo foi utilizado durante o mês de fevereiro de 2002, para a obtenção de 190 medidas pontuais de resistividade ao longo das estradas que cortam a área de visitação do JBB (Fig. 4). Ao todo, foram necessários sete dias para aquisição dos dados de resistividade.

Trabalhos de gamaespectrometria já haviam sido realizados no JBB, em setembro de 2000. Estes trabalhos destinaram-se a verificar se era possível a distinção entre as várias unidades de solos por meio desta propriedade. As medidas não foram realizadas visando a um levantamento sistemático, como no caso das medidas de resistividade, e por este motivo, o volume de dados, embora representativo para a área de estudo, é bastante reduzido. 
O equipamento utilizado foi obtido por empréstimo junto ao Departamento de Geologia da Universidade Federal do Paraná. Trata-se de um gamaespectrômetro portátil, modelo GS-512, fabricado por Geofyzika, República Tcheca, projetado para operar com 512 canais, na faixa de 0,1 a $3 \mathrm{MeV}$. O equipamento compõem-se de 2 módulos, sonda e console, respectivamente. A sonda tem formato cilíndrico, mede $45 \mathrm{~cm}$ de comprimento por $12,5 \mathrm{~cm}$ de diâmetro e pesa $4,6 \mathrm{~kg}$. Trata-se de um invólucro de alumínio que contém o detetor, no caso um cristal de iodeto de sódio ativado por tálio ( $\mathrm{NaI}(\mathrm{TI})$ ), medindo 7,6 x 7,6 cm, o circuito eletrônico de detecção, e uma fonte radioativa de referência $\left({ }^{137} \mathrm{Cs}\right)$. O console mede $23,5 \mathrm{x}$ $23 \times 9 \mathrm{~cm}$, pesa $2,8 \mathrm{~kg}$ e contém os circuitos para armazenagem e processamento dos sinais medidos.

As medições gamaespectrométricas foram realizadas em setembro de 2000. Neste período, visitaram-se 9 locais no JBB: R1, R2, R4, R5, R9, R12, R13, R14 e R15 (Fig. 4). Durante a obtenção das leituras, a sonda permaneceu apoiada verticalmente no solo por 3 minutos, período durante o qual mediram-se as radiações associadas ao ${ }^{40} \mathrm{~K},{ }^{238} \mathrm{U},{ }^{232} \mathrm{Th}$ e contagem total. O período, ou tempo, de medição pode ser ajustado para qualquer valor entre 1 segundo e 24 horas. Contudo, o fabricante do equipamento sugere 4 minutos como valor padrão. O tempo de 3 minutos tem sido utilizado rotineiramente, por usuários deste equipamento em trabalhos deste tipo. Em cada ponto assinalado na figura 6, posicionou-se a sonda em 3 locais, definindo-se um triângulo com cerca de 3 metros de lado no terreno. Este procedimento possibilitou a aquisição de 3 conjuntos de medidas radiométricas em cada ponto, totalizando 108 medidas na área de estudo. Os critérios para escolha dos pontos de medida foram a proximidade com algum perfil de solo descrito e a representatividade do local em relação ao tipo de solo.

Os parâmetros de correção da radiação de fundo foram obtidos a partir de medidas realizadas ao início e ao final de cada dia de trabalho. Estas medidas foram obtidas sobre o lago Paranoá (Fig. 1), utilizando-se para tanto de um cais de madeira, o qual possibilitou levar o equipamento até um local onde a lâmina de água era de 1,5 metros, aproximadamente.

As correções de tempo morto, deriva de energia, radiação de fundo e interferência entre as séries de decaimento foram efetuadas automaticamente por rotinas instaladas no equipamento, considerando o espectro de calibração da radiação de fundo, medido sobre o lago Paranoá, e parâmetros monitorados durante a aquisição das leituras.

A conversão das medidas de cps para unidades de concentração também pode ser feita pelo equipamento, a partir de constantes de conversão previamente armazenadas. Contudo, durante os trabalhos no JBB, esta conversão resultou em valores muito bai$\mathrm{xos}$, e às vezes negativos, para o potássio. Estes valores negativos provavelmente refletem a dificuldade do aparelho para efetuar a conversão de unidades quando os valores medidos são baixos. No caso do JBB, o volume de potássio trocável, quantificado por análises químicas em amostras de LV e LVA, foi de $0,1 \mathrm{meq} / 100 \mathrm{ml}$. Nos cambissolos este valor chegou a $0,06 \mathrm{meq} / 100 \mathrm{ml}$, valores que podem ser considerados baixos (Nascimento, 2003). Concluiu-se que a tentativa de conversão dos resultados expressos em cps para unidades de concentração poderia resultar em medidas sem significado real, e considerando-se também que alguns cálculos normalmente efetuados com este tipo de dado, como as razões K/ $\mathrm{U}$ e K/Th, pressupõem parâmetros expressos nas mesmas unidades, optou-se por trabalhar exclusivamente com as leituras em cps. Além dos valores naturalmente baixos de potássio encontrados nos solos do JBB, um outro fator pode ter comprometido a expressão dos parâmetros medidos em unidades de concentração. Este fator pode estar relacionado com o local escolhido para medição da radiação de fundo, ou seja, o Lago Paranoá. É possível que a distância do Lago até o local de trabalho e a urbanização de suas margens tenham tornado este local inadequado para servir de referência para os dados coletados no JBB.

RESULTADOS E DISCUSSÃO A análise das medidas radiométricas iniciou-se com o cálculo do valor médio para as leituras obtidas nos locais indicados na figura 4; em seguida, estas médias foram dispostas em ordem decrescente (Figs. 5 e 6). Observou-se que latossolos vermelhos são mais radioativos que vemelho-amarelos e cambissolos, sendo que este fato tem forte correlação com a composição textural, expressa pela soma das frações argila (Ar) e silte (St).

Sabe-se que a capacidade de adsorção dos argilominerais pode favorecer a retenção de isótopos radioativos, portanto espera-se uma correlação positiva entre radioatividade e proporção de argila+silte. A matéria orgânica presente no solo pode atuar de forma semelhante, contribuindo também para o acúmulo destes isótopos. Os latossolos vermelhos têm textura mais fina e mais matéria orgânica e por isto são mais radioativos. O local R 15 parece fugir ao padrão observado, contudo, deve ser lembrado que solos de uma mesma classe podem ter texturas diferentes, assim como solos de classes diferentes podem ter texturas semelhantes. O solo do local R15, por exemplo, é vermelho, mas dentre os locais visitados é o que tem textura mais arenosa ( $81 \%$ de areia fina).

As razões $\mathrm{K} / \mathrm{U}$ e $\mathrm{K} / \mathrm{Th}$ foram particularmente úteis na distin-

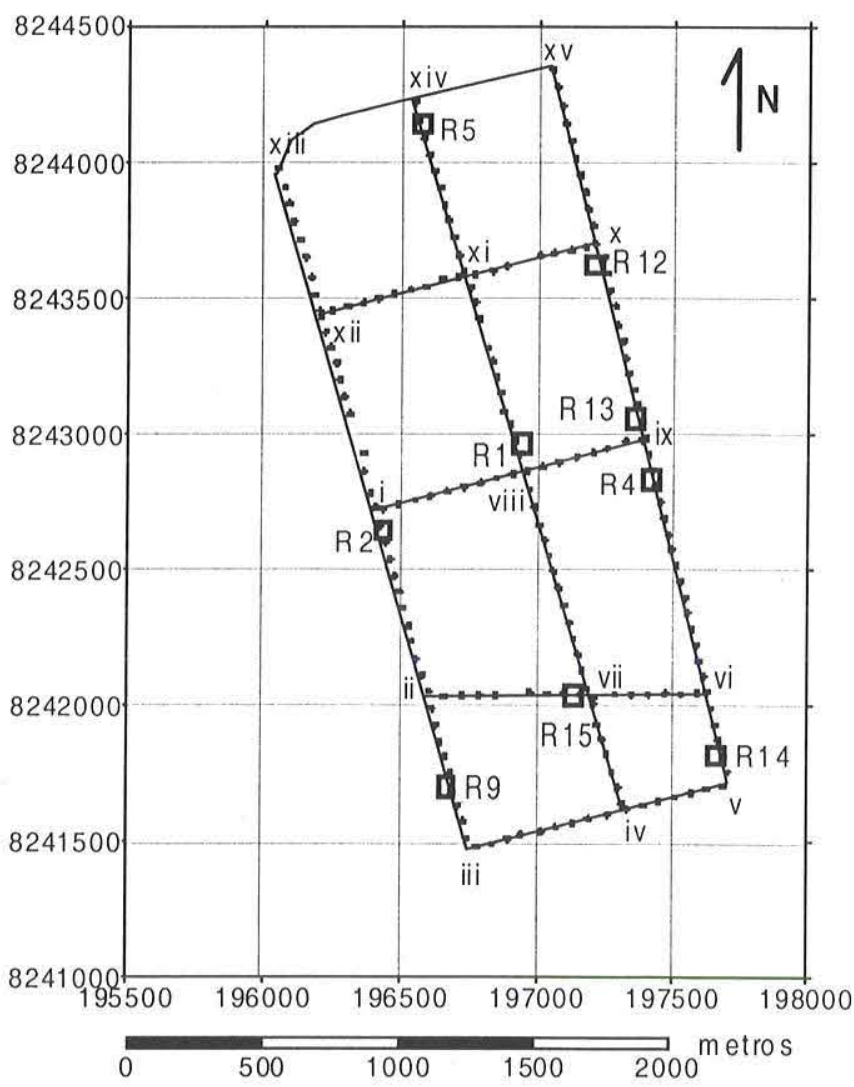

Figura 4 - Localização das medidas de resistividade $e$ radioatividade realizadas no $J B B$. 
ção entre estes solos (Fig. 6). Estas razões indicam que embora os latossolos vermelhos sejam os mais radioativos, a radiação atribuída exclusivamente ao potássio é maior nos vermelho-amarelos e nos cambissolos.

As razões $\mathrm{K} / \mathrm{U}$ e $\mathrm{K} / \mathrm{Th}$ mais elevadas podem ser justificadas pela presença de ilita nos latossolos vermelho-amarelos e cambissolos, bem como por sua ausência nos latossolos vermeIhos. Este argilomineral potássico foi identificado em análises mineralógicas por difratometria de raios $\mathrm{X}$ em amostras de solo coletadas no JBB (Nascimento 2003).

As 190 medidas de resistividade aparente foram interpoladas por meio de krigagem. Na krigagem, a localização geográfica de cada medida influencia diretamente a determinação de cada ponto interpolado e conseqüentemente, o traçado das linhas de contorno. As medidas disponíveis são utilizadas de forma ponderada para estimar valores em áreas não amostradas, sendo que a ponderação se relaciona com a taxa de variação entre as medidas em uma dada orientação. Esta taxa por sua vez, é determinada calcu-
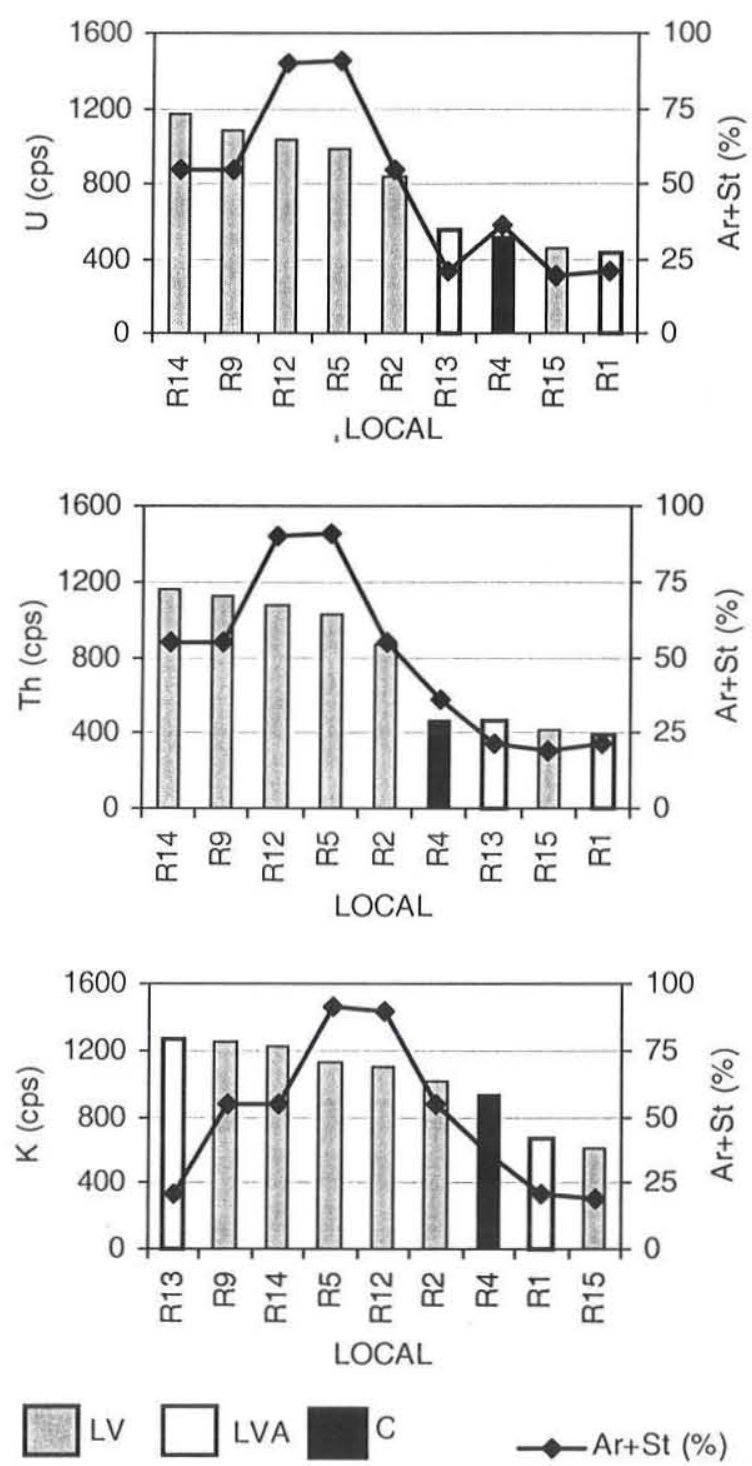

Figura 5 - Radiação gama (U, Th e $K$ ) nos locais visitados em setembro de 2000. lando-se a semivariância $(\gamma)$, equação I, onde X é uma medida da variável na posição $\mathrm{i}, \mathrm{n}$ é o número de intervalos entre medidas numa dada orientação, e h é o valor do intervalo em unidades de comprimento (Davis 1986).

$$
\gamma=\frac{\sum_{i=1}^{n-h}\left(x_{i}-x_{i+h}\right)^{2}}{2 \cdot n}
$$

A semivariância pode ser calculada para vários espaçamentos (n.h) na orientação escolhida, e representada graficamente como função do espaçamento $(\gamma(h))$. Este gráfico recebe o nome de variograma e a curva traçada pode ter diferentes comportamentos, como o linear e o parabólico.

Durante o processamento das medidas de resistividade, calcularam-se os variogramas correspondentes aos perfis iii-xiii, ivxiv e $v-x v$ (Fig. 7). Estes perfis foram escolhidos por atravessarem a maioria das unidades de solos e por concentrarem o maior número de medidas. Verificou-se um bom ajuste de funções lineares aos variogramas, especialmente no perfil iv-xiv. Este fato levou à utili-
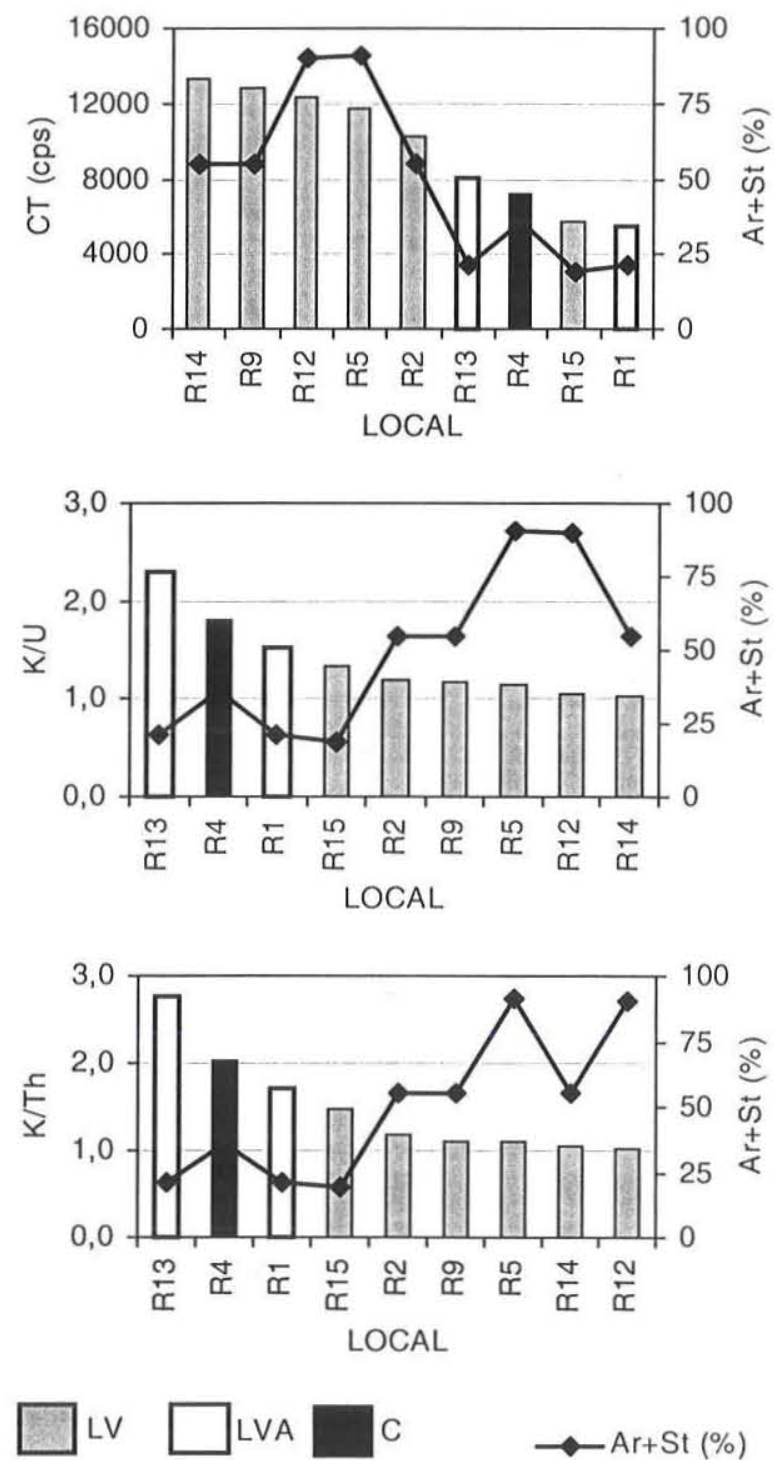

Figura 6 - Radiação gama (contagem total, $K / U$ e $K / T h$ ) nos locais visitados em setembro de 2000. 

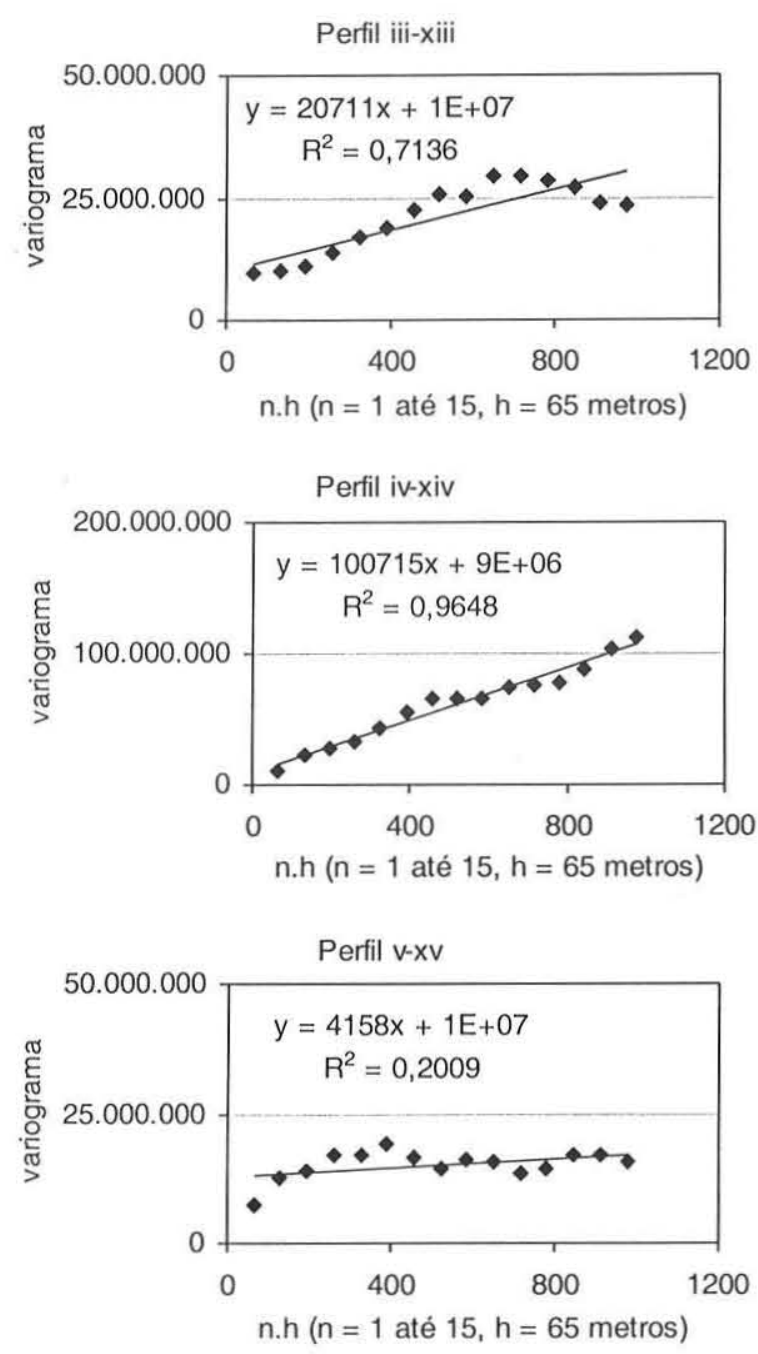

Figura 7 - Variogramas construídos no JBB, a partir das medidas de resistividade aparente.

zação da krigagem com variograma linear para interpolar as medidas de resistividade aparente. A interpolação é o processo durante o qual obtém-se um conjunto de medidas regularmente distribuídas no terreno, a partir de um conjunto irregular de medidas. $\mathrm{O}$ programa computacional empregado foi o SURFER 6.04, Golden Software Inc.

Obteve-se uma malha com 1450 células quadradas, com 60 metros de lado. $\mathrm{O}$ tamanho da célula foi escolhido em função da distância entre os pontos de medição, cerca de $65 \mathrm{~m}$. Os valores da resistividade aparente foram contornados por linhas de igual resistividade com intervalos de $5000 \mathrm{Ohm} . \mathrm{m}$, chegando-se ao mapa mostrado na figura 8 .

Este mapa mostra duas zonas bem diferenciadas. A primeira, com valores de resistividade abaixo de $15000 \mathrm{Ohm} . \mathrm{m}$, tem distribuição mais ampla, coincidindo com as unidades $\mathrm{LV}$, definidas por Cavedon \& Sommer (1990) (Fig. 2). A segunda, com valores superiores a $15000 \mathrm{Ohm} . \mathrm{m}$, é mais restrita, ocorre apenas na porção central da área percorrida e coincide com as unidades LVA, Ce RL.

A relação entre resistividade, umidade e textura pode ser analisada tanto em relação às características físicas do solo, como em relação à sua composição química, e conseqüentemente, mineralógica. Uma textura mais fina traduz-se, geralmente, em poros mais reduzidos, os quais favorecem a retenção de umidade. Textura mais arenosa implica, geralmente, em poros maiores, que facilitam o escoamento da água. Estas considerações são confirmadas pelos valores de condutividade hidráulica disponíveis para a área de estudo, maiores para solos arenosos e menores para solos argilosos. Quanto maior a umidade e quanto maior o conteúdo de íons em solução na água subsuperficial, menos resistivo eletricamente torna-se o solo (Tabbagh et al. 2000).

Do ponto de vista químico e mineralógico, solos de textura fina, em geral, têm mais argilominerais, ao passo que, solos arenosos, em geral, têm mais quartzo na fração granulométrica areia. Sabe-se que a capacidade de adsorção dos argilominerais tornaos bons condutores elétricos, fazendo com que solos arenosos sejam mais resistivos que solos argilosos.

Banton et al. (1997), trabalhando com solos aluviais no Canadá, realizou medições de resistividade em uma área agrícola, as quais foram correlacionadas com a textura dos solos. Observouse uma relação inversa entre teor de argila+silte e resistividade, resultado este semelhante ao que foi obtido no JBB.

Na região central do Brasil, o clima caracteriza-se por duas estações bem delimitadas, uma chuvosa e outra seca. Sabendo que o conteúdo de água no solo influencia diretamente o valor da resistividade, é de se esperar uma variação neste parâmetro no decorrer do tempo. Nascimento et al. (2003), trabalhando no JBB, observaram que solos argilosos mostram valores entre 8000 e 10000 $\mathrm{Ohm} . \mathrm{m}$, em correspondência à passagem da estação chuvosa para a seca. Nos solos arenosos, o valor desta propriedade variou de 20000 até 60000 Ohm.m no mesmo período. A importância destes valores está no fato de demostrarem que é possível diferenciar solos argilosos e arenosos com base em medidas desta propriedade, independente da época do ano.

As unidades LV são mais argilosas, ao passo que as demais são predominantemente arenosas. Deste modo, é possível explicar o contraste de resistividade como resultado de variações texturais. Entretanto, não se observam maiores semelhanças entre os mapas de resistividade (Fig. 8) e de solos (Fig. 2). Esta falta de semelhança pode estar relacionada com as diferenças entre os processos de confecção dos dois mapas.

O mapa de resistividade representa um conjunto regularmente distribuído de valores desta propriedade, obtidos pela interpolação de 190 leituras realizadas exclusivamente nas estradas, e contornadas por linhas de isovalores. É possível que a influência da distribuição irregular dos dados originais tenha se preservado após a krigagem, fazendo com que valores excessivamente altos ou baixos influenciassem no traçado das linhas de contorno.

O mapa de solos representa o resultado de um trabalho de fotointerpretação, sobre uma fotografia aérea, seguido de observação visual no campo e refinamento a partir de análises de solo. A distribuição destas unidades pode ser vista de forma aproximada na figura 2 . Trata-se de uma representação aproximada, principalmente pelo tipo de transição entre as unidades de solo, que é gradual e não abrupto, como leva a crer o traçado dos contornos entre as unidades pedológicas.

Estas diferenças e limitações entre os processos de elaboração dos mapas de solos e de resistividade aparente fazem com que os limites entre as unidades pedológicas sejam considerados como um indicativo do que as medidas geofísicas devam expressar e não um referencial de precisão para estas medidas.

Conforme mencionado, as medidas gamaespectrométricas não 


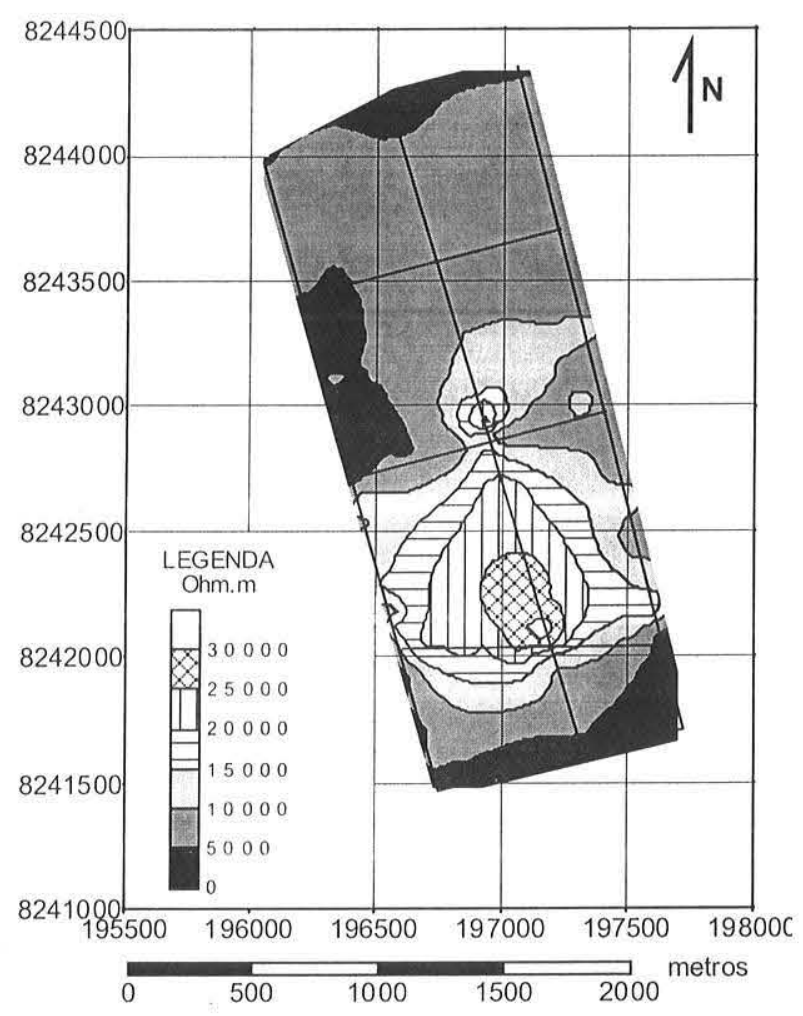

Figura 8-Mapa de resistividade aparente do JBB, obtido com arranjo de Wenner e espaçamento de 2 m entre eletrodos.

foram obtidas com o objetivo de se realizar um levantamento sistemático. No entanto, uma vez que estas medidas podem ser interpoladas, existe a possibilidade da construção de mapas radiométricos. Estes mapas foram gerados durante o processamento dos dados e julgou-se interessante apresentar ao menos aquele correspondente à contagem total (Fig. 9).

O mapa de contagem total mostra uma região de baixa radioatividade, coincidente com os solos arenosos, circundada por outra mais radioativa, coincidente com os solos argilosos. Assim como no mapa de resistividade, não se observam maiores semeIhanças com o mapa de solos disponível. Neste caso, além da distribuição irregular dos pontos de medida, tem-se a pequena densidade de amostragem como fatores capazes de comprometer a qualidade do produto gerado.

Como procedimento para tentar delimitar unidades de solos com base exclusivamente nas medidas geofísicas, efetuou-se uma análise de agrupamentos considerando-se os valores de resistividade aparente, contagem total, $\mathrm{K}, \mathrm{U}$, Th, $\mathrm{K} / \mathrm{U}$ e $\mathrm{K} / \mathrm{Th}$, calculados para cada uma das 1450 células nas quais foi dividida a área de estudo. De modo a que estas variáveis fossem combinadas, foi necessário padronizá-las, subtraindo-se cada valor de uma dada variável da média aritmética e dividindo-se a diferença pelo desvio padrão (Davis 1986).

Utilizando-se os dados interpolados e padronizados, efetuouse a análise de agrupamentos, tentando-se dividir as 1450 células em conjuntos. O critério para efetuar a distribuição foi o de maximizar as diferenças entre os grupos e minimizar as diferenças dentro de cada grupo, considerando a distância numérica entre os valores de cada variável de uma dada célula, até um valor central de cada variável, representativo de cada grupo. Empregou-se o programa STATISTICA 5.0, Statsoft Inc. A distância numérica foi calculada conforme a equação 2 , onde "J" e "K" são duas variáveis quaisquer e "n" é o número de medidas de cada variável.

$$
d(J, K)=\sqrt{\frac{\sum_{i=1}^{n}\left(J_{i}-K_{i}\right)^{2}}{n}}
$$

O programa SURFER 6.04, Golden Software Inc. foi utilizado para representar o resultado das classificações. A cada célula foi atribuído um símbolo, conforme o grupo no qual ela se enquadrou e o resultado da classificação em 5 grupos pode ser observado na figura 10.

Na porção norte da área, região de solos argilosos, ocorrem os os grupos 1,2 e 4 de forma misturada. Na porção central, região de solos arenosos, ocorrem os grupos 3 e 5 , também de forma misturada. Na porção sul ocorrem os grupos 2 e 4 , de forma individualizada. Comparando a distribuição dos agrupamentos estatísticos com o mapa de solos disponível, observa-se que é possível distinguir entre solos argilosos e arenosos embora, no caso da área de estudo, não seja possível diferenciar as unidades argilosas LVI, LV2 e LV3 entre si, o mesmo ocorrendo entre as unidades arenosas LVA1, C2, C3eRL2.

Da mesma forma que a resistividade, sabe-se que efeitos sazonais podem afetar medições radiométricas, aumentando ou reduzindo o contraste dos solos quanto aos parâmetros medidos. No caso da área de estudo, os dados radiométricos foram obtidos em condições de seca, ao passo que os dados de resistividade foram obtidos em uma época chuvosa.

Embora se saiba que maiores conteúdos de água no solo pos-

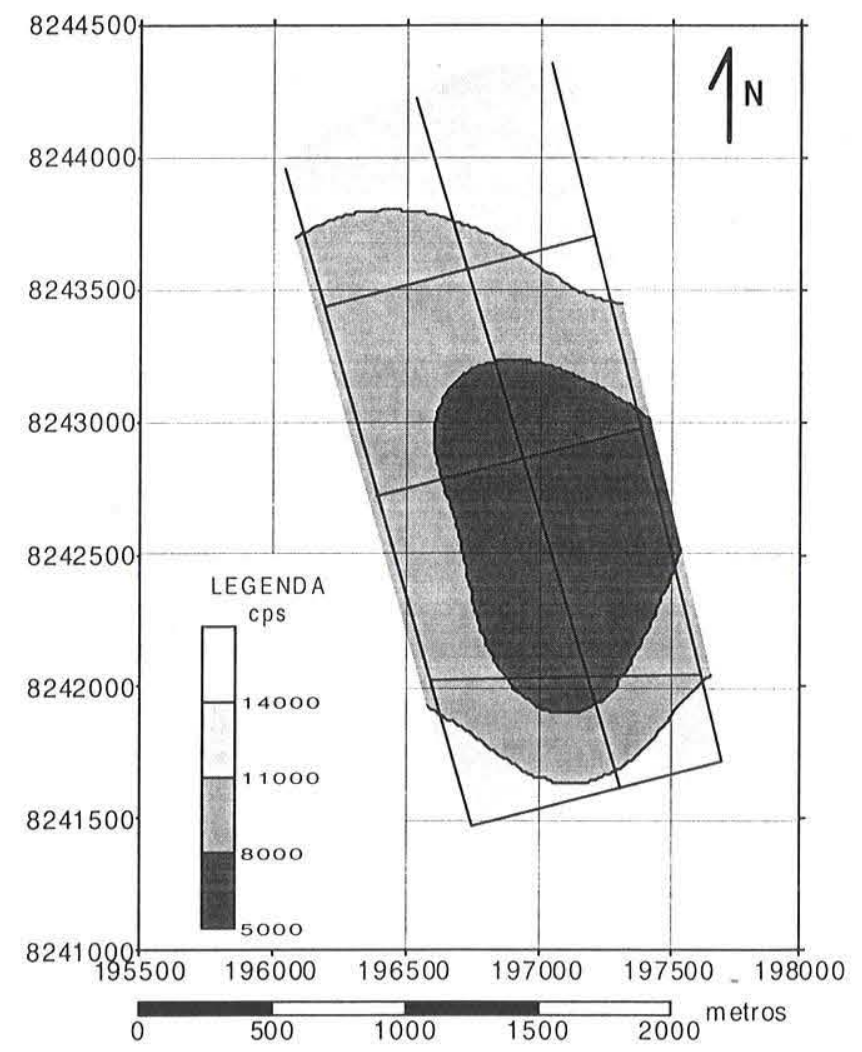

Figura 9 - Mapa radiométrico de contagem total. 


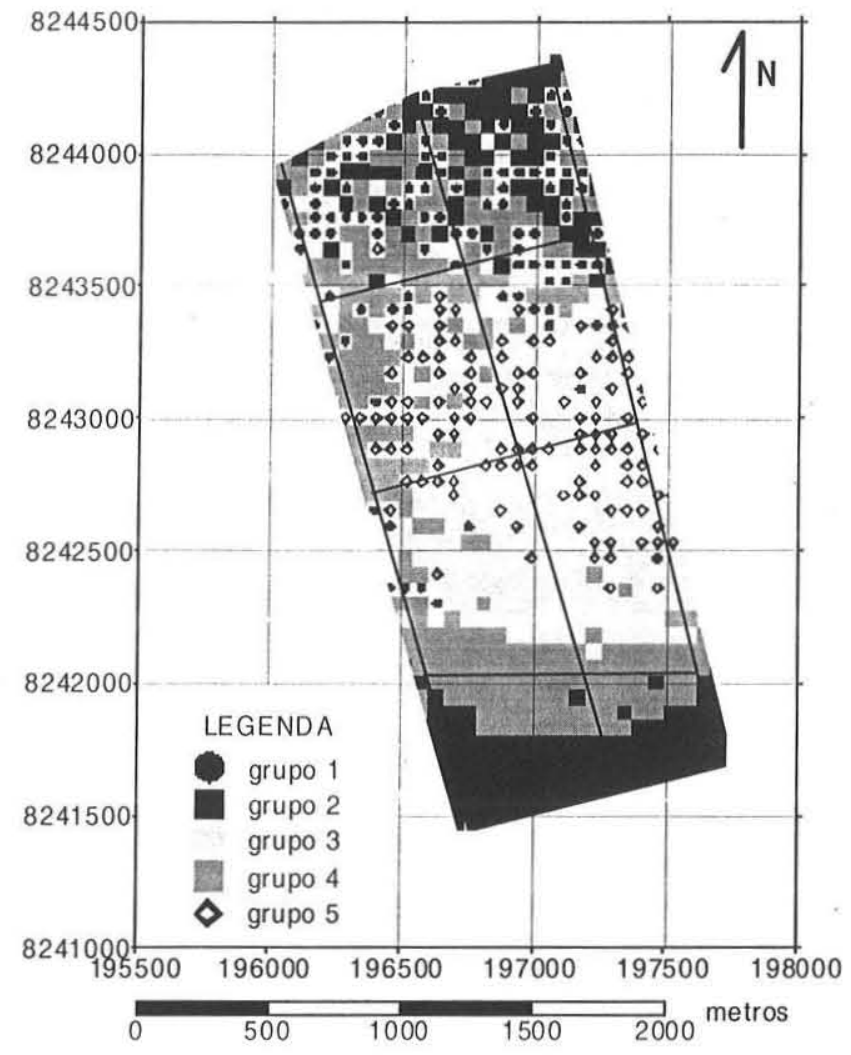

Figura 10 - Resultado da classificação em 5 grupos.

Sam atenuar a emissão de radiação, não se conhece, até o momento, o tipo de variação no contraste radiométrico entre os solos existentes na área de estudo, vinculado à alternância entre as estações chuvosa e seca. É provável que uma integração de dados de resistividade e radiométricos, ambos obtidos em condições de maior contraste, com uma distribuição regular dos pontos de medida e com uma densidade de amostragem compatível com a distribuição das unidades de solo, forneça um produto mais facilmente correlacionável com o mapa de solos disponível.

CONCLUSÕES Os resultados demonstram que é possível distinguir solos arenosos de argilosos com base em medidas geofísicas, no caso resistividade elétrica e radiação gama. No caso da área de estudo observaram-se valores de resistividade aparente abaixo de 15000 Ohm.m para solos argilosos e entre 15000 e $30000 \mathrm{Ohm}$.m para solos arenosos. A explicação para como a textura pode causar a variação na resistividade parece residir na forma como ela influencia os comportamentos físico e químico do solo. Do ponto de vista físico, a textura mais fina proporciona maior porosidade, mas com a formação de espaços intergranulares relativamente pequenos que dificultam o escoamento da água. De forma simplificada, os solos argilosos tendem a reter mais água que os arenosos, e deste modo, têm a condução da eletricidade pelos íons em solução na água intersticial facilitada. Do ponto de vista químico e mineralógico, os solos de textura fina têm quantidades relativamente grandes de argilominerais e pequenas de quartzo, o inverso ocorrendo com os solos arenosos. Deste modo, tem-se que a condução elétrica derivada de íons metálicos adsorvidos tende a ser maior nos solos argilosos, contribuindo, portanto para a sua menor resistividade. Observaram-se maiores níveis de radioatividade sobre os solos argilosos, cujos valores de contagem total ficaram entre 8000 e $14000 \mathrm{cps}$, ao passo que os solos arenosos mostraram valores entre 5000 e $8000 \mathrm{cps}$. A adsorção exercida pelos argilominerais atua não só sobre íons metálicos, mas também sobre os isótopos radioativos, justificando o fato de que os solos argilosos são mais radioativos que os arenosos. Observou-se que, na área de estudo, embora os solos argilosos sejam os mais radioativos, as razões $\mathrm{K} / \mathrm{U}$ e $\mathrm{K} / \mathrm{Th}$ são mais elevadas nos arenosos, fato este que deve estar relacionado à presença de argilomineral potássico nos arenosos. A análise de grupos mostrou-se eficaz no processamento dos dados geofísicos, possibilitando uma integração entre estas informações e fornecendo um resultado que permite discriminar solos argilosos e arenosos.

Agradecimentos Ao CNPq pelo financiamento da pesquisa. A $\mathrm{Sr}^{3}$ Anajúlia Heringer Salles, diretora do JBB, por autorizar a execução do trabalho de campo. Ao professor Francisco J. F. Ferreira (UFPr) pelo empréstimo do gamaespectrômetro. Ao geólogo Maximilian Forlin pelo auxílio na obtenção dos dados gamaespectrométricos. À Profa. Edi Mendes Guimarães pelas análises de raios$\mathrm{X}$ e à Profa. Maria Leonor R. C. L. Assad pelad sugesstões ao original. Aos revisores da RBG pelas críticas e sugestões ao manuscrito.

\section{Referências}

Apparao A. 1991. Geoelectrical profiling. Geoexploration, 27:351-389.

Banton O., Seguin M.K., Cimon M.A. 1997. Mapping field scale physical properties of soil with electrical resistivity. Soil Science Society of America Journal, 61:1010-1017.

Barker R.D. 1989. Depth of investigation of collinear symmetrical fourelectrode arrays. Geophysics, 54:1031-1037.

Cavedon A.D. \& Sommer S. 1990. Jardim Botânico de Brasília; Levantamento Semidetalhado dos solos. Fundação Zoobotânica do Distrito Federal, Brasília, 95 pp.

CODEPLAN. 1984. Atlas do Distrito Federal; Volume I. Companhia do Desenvolvimento do Planalto Central, Brasília, 79 pp.

Davis J.C. 1986. Statistics and Data Analysis in Geology. 2.ed. John Wiley \& Sons, New York. 646 pp.
Fetter C.W. 1994. Applied Hydrogeology. 3.ed. Macmillan College Publishing Company, New York. 691 pp.

Fukue M., Minato T., Horibe H., Taya N. 1999. The micro-structures of clay given by resistivity measurements. Engineering Geology, 54:4353.

Hansen D.A. 1975. Geological Applications Manual for Portable Gamma Ray Spectrometers. Exploraniun G. S. Limited, Toronto. 87 pp.

Koefoed O. 1979. Resistivity Sounding Measurements. Elsevier, Amsterdan, 276 pp.

Minty B.R.S. 1997. Fundamentals of airborne gamma-ray spectrometry. AGSO J. Austral. Geol. Geophy., 17:39-50.

Nascimento C.T.C. 2003. Resistividade elétrica e radiação gama natural no estudo de solos sob cerrado nativo. Tese de Doutorado, 
Universidade de Brasília, $111 \mathrm{p}$.

Nascimento C.T.C., Pires A.C.B., Moraes R.A.V. 2003. Variação sazonal da resistividade em latossolos. In: SBGf, Congr: Intern. Soc. Bras. de Geofísica, 8, Rio de Janeiro, Ancis, CD-ROM.

Orellana E. 1972. Prospeccion Geoelectrica en Corriente Continua. Paraninfo, Madrid, $523 \mathrm{pp}$.

Palocci A., Carvalho J.C., Pereira J.H.F., Silva P.R. 1998. Considerações sobre a granulometria de alguns solos do Centro-Oeste. In: Congresso Brasileiro de Mecânica dos Solos e Engenharia Geotécnica, 11, Brasília, Ancis, 2:1001-1005.

Rhoades J.D. \& Ingvalson R.D. 1971. Determining salinity in field soils with soil resistance measurements. Soil Science Society of America Proceedings, 35:54-60.

Robain H., Descloitres M., Ritz M., Atangana Q. Y. 1996. A multiscale electrical survey of a lateritic soil system in the rain forest of Cameroon. J. Appl. Geoph., 34:237-253.

Roy A. \& Apparao A. 1971. Depth of investigation in direct current methods. Geophysics, 36:943-959.

Roy K.K. \& Elliot H.M. 1981. Some observations regarding depth of exploration in D. C. electrical methods. Geoexploration, 19:1-13.

Santos P.C.V. 1996. Estudos da Contaminação de Água Subterrânea por Percolado de Aterro de Resíduos Sólidos - Caso Jockey Club - DF.
Dissertação de Mestrado, Universidade de Brasília, 135p.

SEMATEC. 1994. Mapa Ambiental do Distrito Federal; Escala 1: 150.000. Secretaria do Meio Ambiente, Ciência e Tecnologia, Brasília.

Tabbagh A., Dabas M., Hesse A., Panissod C. 2000. Soil resistivity: a non-invasive tool to map soil structure horizonation. Geoderma, 97:393-404.

Telford W.M., Geldart L.P., Sheriff R.E., Keys D.A. 1985. Applied Geophysics. Cambridge University Press, Cambridge, 860 pp.

Van Nostrand R. \& Cook K.L. 1966. Interpretation of Resistivity Data; Geological Survey Professional Paper 499. United States Geological Survey, Washington, $310 \mathrm{pp}$.

Vasconcellos R.M., Metelo M.J., Motta A.C., Gomes R.D. 1994. Geofísica em Levantamentos Geológicos no Brasil. Companhia de Pesquisa de Recursos Minerais, Rio de Janeiro, 165 pp.

Wilford J.R., Bierwirth P.N., Craig M.A. 1997. Application of airborne gamma-ray spectrometry in soil/regolith mapping and applied geomorfology. AGSO J. Austral. Geol. Geophy., 17:201-216.

Manuscrito A-1432

Recebido em 09 de maio de 2003

Revisão dos autores em 25 de abril de 2004

Revisão aceita em 30 de maio de 2004 